\title{
EXPERIMENTAL INVESTIGATION OF THE WETTABILITY OF PROTECTIVE GLOVE MATERIALS: A BIOMIMETIC PERSPECTIVE
}

\author{
Emilia Irzmańska1', Aleksandra Jastrzębska², Łukasz Kaczmarek², Agnieszka Adamus-Włodarczyk \\ 1 Central Institute for Labour Protection - National Research Institute, Department of Personal Protective Equipment, 48 Wierzbowa, Lodz, Poland \\ 2 Technical University of Lodz Institute of Materials Science and Engineering, Lodz University of Technology, 1/15 Stefanowskiego, Lodz, Poland* \\ Corresponding author. E-mail: emirz@ciop.lodz.pl, agada@ciop.lodz.pl, jastrzebska.aleksandra1@gmail.com
}

\begin{abstract}
:
The objective of the present work was to evaluate the surface wettability of commercially available polymeric protective gloves, as well as to determine the effects of their surface topography in conjunction with the glove material on the hydrophobic properties of the final products, together with surface free energy (SFE) and work of adhesion.

The geometric structures imparted to the surface led to different levels of hydrophobicity and SFE. Most of the studied materials were characterized by good wettability properties. It was shown that a textured surface topography affects wettability. The highest SFE was found for nitrile butadiene rubber materials. All materials except for nitrile butadiene rubber exhibited good hydrophobic properties and relatively low work of adhesion.
\end{abstract}

\section{Keywords:}

Protective gloves, surface free energy, wettability, hydrophobic properties

\section{Introduction}

Over the past years, the dynamic development of polymeric materials has fueled efforts to design new application solutions in personal protective equipment (PPE) [1, 2]. In turn, the emergence of new hazards in the workplace and the necessity to better adapt PPE to the individual needs of users has motivated research that is focused on the implementation of innovative technologies and materials in that respect [3-5].

Protective gloves fall under the provisions of the Regulation 2016/425 of the European Parliament and of the Council of 9 March 2016 on PPE and repealing Council Directive 89/686/ EEC [6]. The Long Term Personal Protective Equipment Perspective of the European Union contains guidelines in terms of, e.g., the development of functional and unconventional material solutions in PPE design within the 2020 time horizon. This issue has also been emphasized in the document of the ISO Technical Committee [7]. In turn, the need for research on unconventional PPE was recognized by the CEN-CENELEC BT/WG 8 group and the Technical Committee Ergonomic Quality in Design (EQUID) of the International Ergonomics Association (IEA). Protective polymeric gloves may be made of such materials as natural rubber, polychloroprene rubber (neoprene), polyacrylonitrile rubber (perbunan), butyl rubber, Viton, polyvinyl chloride, polyvinyl alcohol, and Hypalon. They may also feature short or long cuffs protecting part of or entire forearms or arms. The palmar surface of polymeric gloves may be textured (covered with fine geometric patterns or projections). In workplace settings, textured surfaces decrease glove slip, facilitate the gripping of smooth, slippery, and wet objects, as well as enable adhesion [8].

Polymeric materials have been used in the manufacture of protective gloves due to their specific physicochemical properties. A variety of treatment methods are available for the design of structural solutions suitable for the intended purpose. Of particular importance are the hydrophobic properties of polymeric surfaces $[9,10]$, which are often determined by their morphology and roughness, as well as chemical composition. The application of, amongst others, fluorine compounds, leads to very low values of surface free energy (SFE). The most popular groups of materials with these properties include those containing fluorofunctional silicon compounds, which exhibit high contact angles with polar liquids - up to $146^{\circ}$ [11]. The hydrophobic properties of protective materials are particularly relevant for safety, as they decrease the risk of the accumulation of chemical and biological contaminants on the glove surface, preventing the hazards associated with the presence of noxious substances in the palmar region and alleviating impairments to hand dexterity. Polymers also exhibit adhesive properties, which constitute another significant aspect of the design of protective gloves. Most commercial polymers, polymeric resins, and composites have low SFE (often $<40 \mathrm{~mJ}$ / $\mathrm{m}^{2}$ ) [12]. They often do not have polar groups on the surface, which results in weak adhesive properties. This has given rise to a major strand of research aimed at gaining a better 
understanding of polymer adhesion, motivated by the growing needs of multiple sectors in terms of improved adhesion of components and coatings $[13,14]$.

There is already a substantial body of literature on the surface treatment of polymers, and especially rubbers (both vulcanized and non-vulcanized), by chemical modification with acids and oxidants. Treatment methods have been developed to improve surface polarity, which increases molecular attraction between objects, thus enhancing adhesion [15].

An alternative to the design of new polymeric glove materials is biomimetic design to obtain materials with targeted properties [16-20]. Before deploying a biomimetic design process in the area of novel materials, it is necessary to evaluate the existing situation, determine the state of the art, define what should be designed/improved, and identify the target applications of the new material, as well as the morphological and structural parameters that need to be obtained to ensure the desired functional properties [21].

In designing protective gloves, an inspiration of great application value is the "lotus leaf effect" patented in 1988. Ever since then, researchers have striven to imitate the superhydrophobic phenomenon. The surface of lotus leaves, which is the most popular example of a surface with superhydrophobic and self-cleaning properties, is naturally covered with submicron, hierarchically arranged microscopic papillae with the size of 20-50 $\mu \mathrm{m}$, which themselves feature 0.5-3.0 $\mu \mathrm{m}$ micropapillae and are additionally covered with organic wax [22]. Another interesting superhydrophobic mechanism was found in the Salvinia floating fern, whose leaves are covered with hydrophobic hairs trapping an air layer upon submersion, while the tips of the hairs are hydrophilic. This effect has informed an innovative method of development of biomimetic surfaces with superhydrophobic properties using an air-retaining mechanism for underwater applications [23].

An interesting concept derived from observations of nature and the aforementioned hypothetical models is that surfaces may not only be functionalized to obtain low wettability, but indeed a superhydrophobic effect and self-cleaning properties may be imparted via micro- or nanostructures [24]. Amongst others, Guo et al. [25] addressed the question of how various surface morphologies of plants affect wettability. It was found that hierarchical micro- or nanostructures are not indispensable for the formation of superhydrophobic surfaces, as they may also be produced by mimicking other structures, e.g., an irregular arrangement of hairs on Chinese watermelons.

It is often the case that the structures formed on the surface of a material may exhibit much higher hydrophobicity as compared to the same material without a specific topography [26]. The SFE of the material modified by rough pattern or the presence of micro- or nanostructures may also significantly affect the initial stages of the adhesion of biological material or other contaminants. Therefore, it may be inferred that a combination of very low surface energy and a hierarchical structural configuration on the surface may, e.g., reduce the contact area between the material and contaminant particles $[27,28]$.

The production of superhydrophobic surfaces inspired by the lotus leaf structure is not an easy process as it requires a technology that would enable the formation of a nanostructural matrix on the modified surface, with a desirable morphology and physicochemical properties. Such technologies usually fall into two groups. One consists of those processes that modify the surface area of materials with low surface energy. The other one involves the application of low surface energy layers on materials with high surface energy [29].

Modification of flurofunctional polymers is not the only means for imparting superhydrophobic properties to materials at the stage of production, since, according to the literature, other polymers may also exhibit hydrophobic surfaces following physical and chemical surface modifications. Such polymers include polystyrene, polypropylene, poly (4-methyl-1-pentene), polyacrylonitrile (PAN), polyamide, and polybenzoxazine [30, 31].

The present work aimed to evaluate the surface wettability (contact angle) of commercially available polymeric protective gloves made of latex, natural latex, a mixture of natural latex with 2-chlorobuta-1,3-diene, nitrile butadiene rubber, butyl rubber, polyvinyl chloride, and 2-chlorobuta-1,3-diene. Another goal was to determine the effects of their surface topography (type and height of projections) in conjunction with the glove material on the hydrophobic properties of the final products. An important element of the study was determination of SFE and work of adhesion. Analysis of these factors in commercially available, widely used, protective gloves will guide future work on the surface modification of polymeric materials with a view to enhance their hydrophobicity. Such research is necessary to improve the safety and user comfort of polymeric protective gloves by enabling better hand dexterity under unfavorable use conditions, especially in contact with wet and contaminated objects.

\section{Experimental}

\subsection{Materials}

The study involved polymeric protective gloves that are commercially available and widely used. The gloves were divided into groups depending on their constituent materials, i.e., latex, natural latex, a mixture of natural latex with 2-chlorobuta-1,3-diene, nitrile butadiene rubber, butyl rubber, polyvinyl chloride, and 2-chlorobuta-1,3-diene. The study also examined the effects of the geometric surface textures imparted to the materials during the technological process.

Table 1 presents material samples, manufacturers' data, and photographs of the textured surfaces of protective gloves. Gloves made of latex, natural latex, 2-chlorobuta-1,3-diene, and a mixture of natural latex with 2-chlorobuta-1,3-diene exhibited projections throughout their palmar aspects, which, however, did not affect their thickness. Nitrile butadiene rubber 
gloves were the thinnest $(0.20 \mathrm{~mm}$ and $0.46 \mathrm{~mm})$, while latex ones were the thickest $(1 \mathrm{~mm})$.

\subsection{Methods}

\subsubsection{Evaluation of surface morphology/texture}

Texture height, i.e., the height of surface projections (W), was determined from the difference between the thickness of the textured dorsal aspect (M) and the smooth palmar aspect (D). Material thickness was measured using a thickness gauge (PP-
U Instrom, Piastów, Poland) under supervision in an accredited laboratory and calculated from Eq. (1):

$$
W=M-D
$$

\subsubsection{Evaluation of surface wettability}

The surface wettability of commercial protective gloves was measured by means of the sessile drop method, using a Phoenix Alpha contact angle analyzer from SEO (USA). Drops were placed on the sample surface using an automated

Table 1. Characteristics of the studied glove material samples.

\begin{tabular}{|c|c|c|c|c|c|c|c|}
\hline Material & $\begin{array}{c}\text { Sample no., } \\
\text { commercial } \\
\text { name, } \\
\text { manufacturer }\end{array}$ & $\begin{array}{c}\text { Thickness } \\
\text { (mm) }\end{array}$ & Palmar surface & Material & $\begin{array}{l}\text { Sample no., } \\
\text { commercial } \\
\text { name, } \\
\text { manufacturer }\end{array}$ & $\begin{array}{c}\text { Thickness } \\
(\mathrm{mm})\end{array}$ & Palmar surface \\
\hline \multirow{5}{*}{$\begin{array}{l}\text { Natural } \\
\text { latex }\end{array}$} & $\begin{array}{c}\text { Sample } \\
1 \text { (CHEM } \\
\text { PROTEC } \\
3250, \\
\text { NITRAS) }\end{array}$ & $0.92 \pm 0.01$ & & $\begin{array}{c}\text { Natural } \\
\text { latex }+ \\
\text { 2-chlorobuta- } \\
\text { 1,3-diene }\end{array}$ & $\begin{array}{c}\text { Sample } 9 \\
\text { (CAMA PREN } \\
722, \mathrm{KCL} \text { ) }\end{array}$ & $0.74 \pm 0.01$ & \\
\hline & $\begin{array}{c}\text { Sample } 2 \\
\text { (CPMBI } \\
\text { LATEX, KCL) }\end{array}$ & $0.96 \pm 0.05$ & & \multirow{4}{*}{$\begin{array}{l}\text { Nitrile } \\
\text { butadiene } \\
\text { rubber }\end{array}$} & $\begin{array}{c}\text { Sample } 10 \\
\text { (743 Dermatril, } \\
\text { KCL) }\end{array}$ & $0.20 \pm 0.01$ & \\
\hline & $\begin{array}{l}\text { Sample } 3 \\
\text { (LUDWIK, } \\
\text { LARKIS) }\end{array}$ & $1.09 \pm 0.03$ & & & $\begin{array}{c}\text { Sample } 11 \\
\text { (TEVUCHEM, } \\
\text { KCL) }\end{array}$ & $1.27 \pm 0.04$ & \\
\hline & $\begin{array}{c}\text { Sample } 4 \\
\text { (CAMATEX } \\
4517, \mathrm{KCL})\end{array}$ & $1.70 \pm 0.08$ & & & $\begin{array}{c}\text { Sample } 12 \\
\text { (CAMATRIL } \\
730, \mathrm{KCL})\end{array}$ & $0.46 \pm 0.01$ & \\
\hline & $\begin{array}{c}\text { Sample } 5 \\
\text { (CAMAPREN } \\
720, \mathrm{KCL})\end{array}$ & $0.73 \pm 0.02$ & & & $\begin{array}{c}\text { Sample } \\
13 \text { (3550, } \\
\text { NITRAS) }\end{array}$ & $1.32 \pm 0.04$ & \\
\hline \multirow{3}{*}{ Latex } & $\begin{array}{c}\text { Sample } 6 \text { (535 } \\
\text { Jet Orange, } \\
\text { POLYCO) }\end{array}$ & $1.20 \pm 0.01$ & & Butyl rubber & $\begin{array}{c}\text { Sample } 14 \\
\text { (BUTOJECT } \\
897, \mathrm{KCL})\end{array}$ & $0.67 \pm 0.02$ & \\
\hline & $\begin{array}{c}\text { Sample } 7 \\
\text { (YETI GERIN) }\end{array}$ & $1.06 \pm 0.03$ & 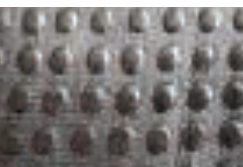 & $\begin{array}{l}\text { Polyvinyl } \\
\text { chloride }\end{array}$ & $\begin{array}{c}\text { Sample } 15 \\
\text { (CAMA ISO } \\
690, \mathrm{KCL})\end{array}$ & $1.54 \pm 0.02$ & \\
\hline & $\begin{array}{c}\text { Sample } 8 \\
\text { (3560 Soft } \\
\text { Grip, NITRAS) }\end{array}$ & $1.37 \pm 0.04$ & & $\begin{array}{l}\text { 2-Chlorobuta- } \\
\text { 1,3-diene }\end{array}$ & $\begin{array}{c}\text { Sample } \\
16 \text { (3460, } \\
\text { NITRAS) }\end{array}$ & $0.78 \pm 0.02$ & \\
\hline
\end{tabular}


syringe. Photographs were taken with the integrated on-board camera and analyzed using Phoenix Alpha software. Ten drops of a bipolar liquid (deionized water) and ten drops of a nonpolar liquid (diiodomethane) were placed on each sample.

The measured contact angle values were used to calculate SFE for the samples. The test liquids differed in their polarity and surface energy: $L=50.8 \mathrm{~mJ} / \mathrm{m}^{2}, \gamma_{L}^{d}=50.8 \mathrm{~mJ} / \mathrm{m}^{2}$, and $\gamma_{L}^{p}=0.0 \mathrm{~mJ} / \mathrm{m}^{2} \quad$ for diiodomethane; and $L=72.8 \mathrm{~mJ} / \mathrm{m}^{2}$, $\gamma_{L}^{d}=21.8 \mathrm{~mJ} / \mathrm{m}^{2}$, and $\gamma_{L}^{p}=51.0 \mathrm{~mJ} / \mathrm{m}^{2}$ for water. SFE $\left(\gamma_{L}\right)$ being the sum of two components-dispersive interactions $\left(\gamma_{L}^{d}\right)$ and non-dispersive, mostly polar, interactions $\left(\gamma_{L}^{p}\right)$ - was determined using the Owens-Wendt method and theoretical model, according to which the dispersive component is associated with Van der Waals bonds and non-specific interactions on the surface, while the polar component arises from hydrogen bonds, dipole-dipole interactions, etc. [32].

SFE was obtained from Eqs (2) and (3):

$$
\begin{aligned}
& \gamma_{L} \frac{1+\cos \theta}{2}=\left(\gamma_{S}^{d} \gamma_{L}^{d}\right)^{0.5}+\left(\gamma_{S}^{p} \gamma_{L}^{P}\right)^{0.5} \\
& \gamma_{S}=\gamma_{S}^{d}+\gamma_{S}^{P}
\end{aligned}
$$

where $\theta$ is contact angle, $\gamma_{S}$ is surface free energy of a solid, $\gamma_{L}$ is surface free energv of a liquid, $\gamma_{L}^{d}$ is dispersive component $\wedge_{d}$ SFE of a liquid, $\gamma_{L}^{p}$ is polar component of SFE of a liquid, $\gamma_{S}^{d}$ is dispersive component of SFE of a solid, and $\gamma_{S}^{p}$ is polar component of SFE of a solid.

\subsubsection{Work of adhesion}

\begin{tabular}{|c|c|c|}
\hline Material & Sample & Projection height [mm] \\
\hline \multirow{5}{*}{ Natural latex } & Sample 1 & $0.29 \pm 0.01$ \\
\hline & Sample 2 & $0.04 \pm 0.01$ \\
\hline & Sample 3 & $0.48 \pm 0.02$ \\
\hline & Sample 4 & $0.31 \pm 0.09$ \\
\hline & Sample 5 & $0.09 \pm 0.03$ \\
\hline \multirow{3}{*}{ Latex } & Sample 6 & $0.50 \pm 0.01$ \\
\hline & Sample 7 & $0.07 \pm 0.04$ \\
\hline & Sample 8 & $0.37 \pm 0.05$ \\
\hline Natural latex + 2-chlorobuta-1,3-diene & Sample 9 & $0.13 \pm 0.01$ \\
\hline \multirow{4}{*}{ Nitrile butadiene rubber } & Sample 10 & $0.06 \pm 0.03$ \\
\hline & Sample 11 & $0.35 \pm 0.06$ \\
\hline & Sample 12 & $0.06 \pm 0.04$ \\
\hline & Sample 13 & $0.43 \pm 0.03$ \\
\hline Butyl rubber & Sample 14 & $0.27 \pm 0.04$ \\
\hline Polyvinyl chloride & Sample 15 & $0.27 \pm 0.04$ \\
\hline 2-chlorobuta-1,3-diene & Sample 16 & $0.03 \pm 0.01$ \\
\hline
\end{tabular}

Table 2. Height of projections on the studied protective glove materials.
Adhesion arises from intermolecular interactions between objects that are in contact with one another. A measure of adhesion is the work of adhesion per unit of area that needs to be performed to separate the adhering objects. Work of adhesion measurements were used to determine the energy state of the surfaces of the studied materials. Measurements were based on the relationship described by the Young-Dupre Eq. (4) [33].

$W_{a}=\gamma_{L}(1+\cos \theta)=2\left(\gamma_{S}^{d} \gamma_{L}^{d}\right)^{\frac{1}{2}}+2\left(\gamma_{S}^{p} \gamma_{L}^{p}\right)^{\frac{1}{2}}$

where $W_{a}$ designates the work required to separate a drop from a solid surface, which is also a good indicator of the wettability of solids.

\subsection{Statistical analysis}

The results were analyzed statistically using SPSS Statistics 25.0 software to evaluate the relationship between the height of geometric projections on glove materials and contact angles. Pearson's $r$ correlation coefficient was calculated by means of a posteriori bootstrapping (1,000 replicates). The statistical significance of results was adopted at $p<0.05$.

\section{Results}

\subsection{Height of projections}

Projection height results for individual samples are shown in Table 2, while the values of mean projection height for the various groups of materials are shown in Figure 1. In general, the height of projections on the studied gloves was in the range 


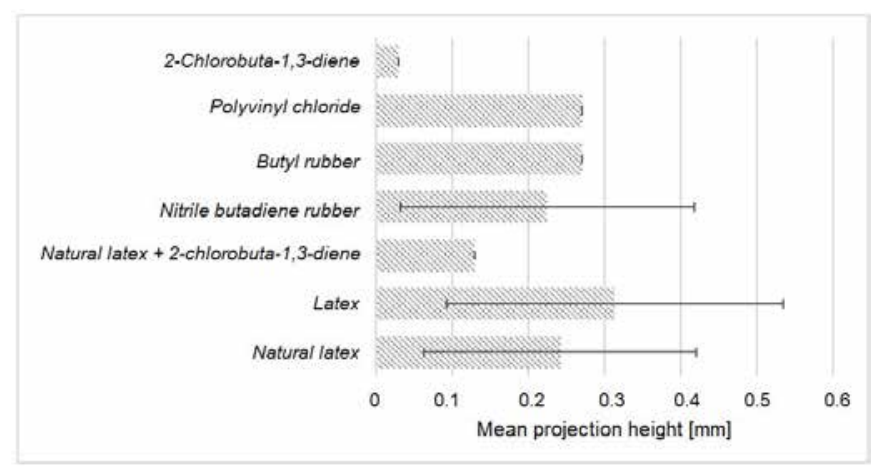

Figure 1. Mean projection height for the studied groups of protective glove materials.

$0.03-0.50 \mathrm{~mm}$, with the mean height for all glove materials being $0.23 \mathrm{~mm}( \pm 0.17)$.

\subsection{Wettability}

Contact angle measurements for the palmar (textured) and dorsal aspects of glove materials are given in Figure 2. Only three samples exhibited hydrophobic properties - two samples made of natural latex (Samples 3 and 4) and one made of latex (Sample 8). Those samples also showed the greatest differences between the contact angles of their palmar and dorsal aspects. High wettability was noted for all nitrile butadiene rubber materials (water contact angle of $20-30^{\circ}$ ). Examples of photographs of water drops on the surface of the studied materials (used for measurement purposes) are given in Table 3.

\subsection{SFE and work of adhesion}

Table 4 presents the polar and dispersive components of the SFE of polymers and work of adhesion measurements $\left(W_{p}-\right.$ work of adhesion for a polar liquid; $W_{d}$ - work of adhesion for a non-polar liquid; $W_{a}$ - total work of adhesion) for the palmar aspect of materials, while Table 5 gives the corresponding results for the dorsal aspect.

The highest surface energy, $69 \mathrm{~mJ} / \mathrm{m}^{2}$, was obtained for nitrile butadiene rubber, as compared to $43-55 \mathrm{~mJ} / \mathrm{m}^{2}$ for the other materials. For all the studied materials, except nitrile butadiene rubber, the polar component contributed more to SFE than the dispersive component, both in the dorsal and palmar aspects. Materials with lower dispersive components also exhibited better water contact angles.

Analysis of work of adhesion for a drop of water (polar liquid) revealed comparable values for all the studied materials. Differences were observed for the dispersive test liquid, with work of adhesion for nitrile butadiene rubber being almost four times greater as that for the other materials, which is attributable to its very good wettability: $22.7^{\circ}$ for the dorsal aspect and $25.9^{\circ}$ for the palmar aspect. It should be noted that nitrile butadiene rubber also exhibited the highest work of adhesion for water.

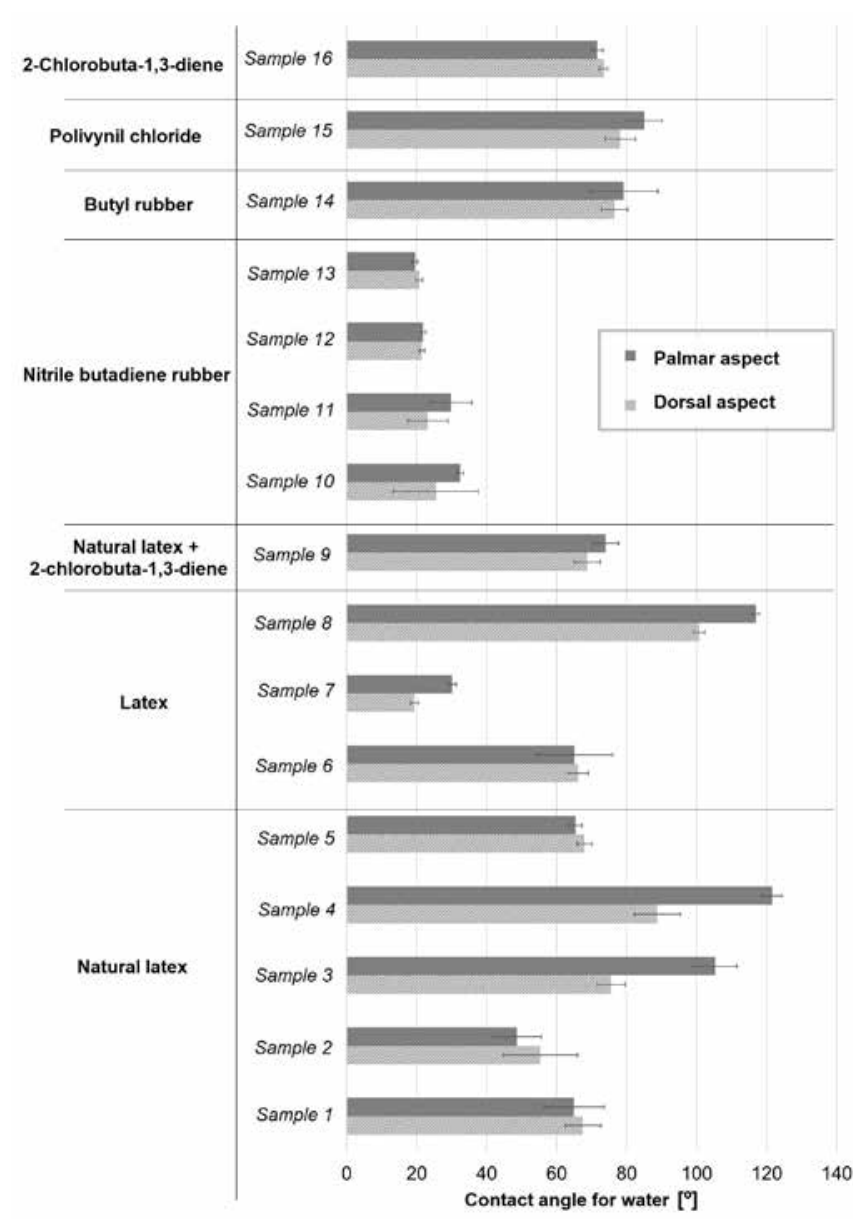

Figure 2. Contact angles for the palmar and dorsal aspects of the studied protective glove materials.

\subsection{Statistical analysis}

Table 6 contains descriptive statistics for the height of geometric projections on the material and contact angles for the dorsal and palmar aspects of protective gloves.

Table 7 gives a Correlation matrix between the height of geometric projections on the material and contact angles for the dorsal and palmar aspects of protective gloves. The results indicated the absence of significant correlations between the studied variables.

Analysis showed that the height of geometric projections on the material is not significantly correlated with contact angles for the dorsal or palmar aspects of protective gloves.

\section{Discussion}

The present study involved sixteen types of commercially available gloves made of latex, natural latex, a mixture of natural latex with 2-chlorobuta-1,3-diene, butyl rubber, polyvinyl chloride, 2-chlorobuta-1,3-diene, and nitrile butadiene rubber. Products within material groups differed in terms of surface morphology - the presence of projections with regular or irregular patterns and thickness (Table 1). 
Table 3. Photographs of drops on the studied protective glove materials (contact angle measurements were used).

\begin{tabular}{|c|c|c|c|}
\hline Material & Sample & Dorsal aspect & Palmar aspect \\
\hline \multirow{5}{*}{ Natural latex } & Sample 1 & & \\
\hline & Sample 2 & & \\
\hline & & & \\
\hline & Sample 4 & & \\
\hline & Sample 5 & & \\
\hline \multirow{3}{*}{ Latex } & Sample 6 & & \\
\hline & Sample 7 & & \\
\hline & Sample 8 & & \\
\hline Natural latex +2 -chlorobuta-1,3-diene & Sample 9 & & \\
\hline \multirow{4}{*}{ Nitrile butadiene rubber } & Sample 10 & & \\
\hline & Sample 11 & & \\
\hline & Sample 12 & & \\
\hline & Sample 13 & & \\
\hline Butyl rubber & Sample 14 & & \\
\hline Polyvinyl chloride & Sample 15 & & \\
\hline 2-chlorobuta-1,3-diene & Sample 16 & & \\
\hline
\end{tabular}


Table 4. Surface properties of the palmar aspect of the studied protective gloves.

\begin{tabular}{|c|c|c|c|c|c|c|c|}
\hline Material & Sample & $\begin{array}{l}\gamma_{S}^{P} \cdot( \\
\left.\mathrm{J}^{\prime} / \mathrm{m}^{2}\right)\end{array}$ & $\gamma_{\left.\mathbf{m}^{2}\right)}^{d}(\mathbf{m} \mathbf{J} /$ & $\gamma_{S}\left(\mathrm{~mJ} / \mathrm{m}^{2}\right)$ & $W_{p}\left(\mathrm{~mJ} / \mathrm{m}^{2}\right)$ & $W_{d}\left(\mathrm{~mJ} / \mathrm{m}^{2}\right)$ & $W_{a}\left(\mathrm{~mJ} / \mathrm{m}^{2}\right)$ \\
\hline \multirow{5}{*}{ Natural latex } & Sample 1 & 35.76 & 12.16 & 47.92 & 83.42 & 35.15 & 118.57 \\
\hline & Sample 2 & 32.98 & 20.97 & 53.95 & 88.24 & 46.16 & 134.39 \\
\hline & Sample 3 & 48.60 & 1.13 & 49.74 & 77.43 & 10.71 & 88.14 \\
\hline & Sample 4 & 52.31 & 5.12 & 57.43 & 87.99 & 22.81 & 110.79 \\
\hline & Sample 5 & 36.51 & 10.26 & 46.77 & 82.18 & 32.29 & 114.46 \\
\hline \multirow{3}{*}{ Latex } & Sample 6 & 34.20 & 10.80 & 45.00 & 80.76 & 33.13 & 113.89 \\
\hline & Sample 7 & 29.68 & 35.18 & 64.86 & 94.19 & 59.79 & 153.97 \\
\hline & Sample 8 & 50.96 & 3.35 & 54.31 & 84.18 & 18.45 & 102.63 \\
\hline $\begin{array}{c}\text { Natural latex }+ \\
\text { 2-chlorobuta-1,3-diene }\end{array}$ & Sample 9 & 38.96 & 5.22 & 44.19 & 78.13 & 23.03 & 101.15 \\
\hline \multirow{4}{*}{ Nitrile butadiene rubber } & Sample 10 & 29.95 & 33.84 & 63.79 & 93.68 & 58.64 & 152.32 \\
\hline & Sample 11 & 29.78 & 34.68 & 64.47 & 94.00 & 59.36 & 153.36 \\
\hline & Sample 12 & 28.82 & 39.65 & 68.47 & 95.80 & 63.47 & 159.27 \\
\hline & Sample 13 & 28.60 & 40.88 & 69.47 & 96.23 & 64.45 & 160.68 \\
\hline Butyl rubber & Sample 14 & 39.71 & 4.05 & 43.76 & 76.93 & 20.28 & 97.22 \\
\hline Polyvinyl chloride & Sample 15 & 42.20 & 1.25 & 43.45 & 72.99 & 11.27 & 84.26 \\
\hline 2-chlorobuta-1,3-diene & Sample 16 & 38.00 & 6.98 & 44.98 & 79.70 & 26.63 & 106.33 \\
\hline
\end{tabular}

Table 5. Surface properties of the dorsal aspect of the studied protective gloves.

\begin{tabular}{|c|c|c|c|c|c|c|c|}
\hline Material & Sample & $\gamma_{S}^{P} \cdot\left(\mathrm{J} / \mathrm{m}^{2}\right)$ & $\gamma_{S}^{d}\left(\mathrm{~mJ} / \mathrm{m}^{2}\right)$ & $\gamma_{S}\left(\mathrm{~mJ} / \mathrm{m}^{2}\right)$ & $\mathrm{W}_{\mathrm{p}}\left(\mathrm{mJ} / \mathrm{m} 2^{2}\right)$ & $\mathbf{W}_{\mathrm{d}}\left(\mathrm{m} J / \mathrm{m}^{2}\right)$ & $\mathbf{W}_{\mathrm{a}}\left(\mathrm{mJ} / \mathrm{m}^{2}\right)$ \\
\hline \multirow{5}{*}{ Natural latex } & Sample 1 & 36.95 & 9.21 & 46.16 & 81.43 & 30.59 & 112.02 \\
\hline & Sample 2 & 36.79 & 12.26 & 49.06 & 84.38 & 35.29 & 119.67 \\
\hline & Sample 3 & 38.62 & 5.81 & 44.44 & 78.68 & 24.30 & 102.98 \\
\hline & Sample 4 & 42.27 & 1.19 & 43.47 & 72.87 & 11.00 & 83.86 \\
\hline & Sample 5 & 36.80 & 9.57 & 46.36 & 81.69 & 31.18 & 112.88 \\
\hline \multirow{3}{*}{ Latex } & Sample 6 & 36.62 & 9.99 & 46.61 & 81.99 & 31.86 & 113.85 \\
\hline & Sample 7 & 28.61 & 40.79 & 69.40 & 96.19 & 64.38 & 160.57 \\
\hline & Sample 8 & 46.07 & 0.05 & 46.11 & 70.03 & 2.25 & 72.28 \\
\hline $\begin{array}{c}\text { Natural latex }+ \\
\text { 2-chlorobuta-1,3-diene }\end{array}$ & Sample 9 & 37.08 & 8.93 & 46.00 & 81.23 & 30.12 & 111.35 \\
\hline \multirow{4}{*}{ Nitrile butadiene rubber } & Sample 10 & 29.19 & 37.70 & 66.89 & 95.11 & 61.89 & 157.00 \\
\hline & Sample 11 & 29.06 & 38.36 & 67.42 & 95.34 & 62.43 & 157.77 \\
\hline & Sample 12 & 28.77 & 39.91 & 68.69 & 95.89 & 63.68 & 159.56 \\
\hline & Sample 13 & 28.73 & 40.13 & 68.86 & 95.96 & 63.85 & 159.82 \\
\hline Butyl rubber & Sample 14 & 38.98 & 5.19 & 44.17 & 78.10 & 22.96 & 101.06 \\
\hline Polyvinyl chloride & Sample 15 & 39.66 & 4.13 & 43.78 & 77.02 & 20.48 & 97.51 \\
\hline 2-chlorobuta-1,3-diene & Sample 16 & 38.28 & 6.45 & 44.72 & 79.26 & 25.60 & 104.86 \\
\hline
\end{tabular}

Table 6. Descriptive statistics for projection height and contact angles for the dorsal and palmar aspects of protective gloves.

\begin{tabular}{|c|c|c|c|c|c|c|c|c|}
\hline Parameter & & $\boldsymbol{N}$ & Min & Max & $\boldsymbol{M}$ & SD & Skewness & Kurtosis \\
\hline Projection height $(\mathbf{m m})$ & & 16 & 0.03 & 0.50 & 0.23 & 0.17 & 0.18 & -1.46 \\
\hline \multirow{2}{*}{ Contact angle $\left(^{\circ}\right)$} & Dorsal aspect & 16 & 19.42 & 100.75 & 58.09 & 26.99 & -0.40 & -1.22 \\
\cline { 2 - 10 } & Palmar aspect & 16 & 19.49 & 121.55 & 64.48 & 32.60 & 0.27 & -0.84 \\
\hline
\end{tabular}


Table 7. Correlation matrix between projection height and contact angles for the dorsal and palmar aspects of protective gloves.

\begin{tabular}{|l|c|c|c|}
\hline & & \multicolumn{2}{|c|}{ Projection height (mm) } \\
\hline & & Pearson's $\boldsymbol{r}$ & $\boldsymbol{p}$ \\
\hline \multirow{2}{*}{${\left.\text { Contact angle ( }{ }^{\circ}\right)}^{*}$} & Dorsal aspect & 0.27 & 0.26 \\
\cline { 2 - 4 } & Palmar aspect & 0.30 & 0.17 \\
\hline
\end{tabular}

Bearing in mind the hydrophobic properties of polymeric gloves, it is also important to obtain a desired surface geometry (texture) of the material. In the studied materials, the mean height of projections was $0.23 \mathrm{~mm}( \pm 0.17 \mathrm{~mm})$, which is consistent with the relevant standards, according to which glove thickness should not exceed $2 \mathrm{~mm}$ (the higher the texture topology, the lower the mechanical properties).

The study evaluated the wettability of the dorsal and palmar surfaces of gloves. The lowest contact angle was obtained for gloves made of nitrile butadiene rubber, which indicates their excellent wettability. Only latex gloves exhibited hydrophobic properties in the dorsal aspect. In the other cases, contact angle was $<90^{\circ}$, which demonstrates hydrophilicity. The effects of geometric textures on wettability were also assessed. It was shown that in most cases, the presence of structural patterns on the surface increased hydrophobicity, irrespective of the type of material. The most favorable results, i.e., the highest water contact angles, were found for latex and natural latex materials with irregular textural roughness patterns.

Similarly, Łagan et al. [34] evaluated the physicochemical properties of different types of disposable polymeric protective gloves made of latex, nitrile, and vinyl. While all the materials displayed hydrophobic properties towards a polar liquid (water), none of them had regular surface texturing.

High contact angles were also reported for protective gloves made of latex, nitrile, and vinyl in the study by Moore et al. [35]. Smooth latex gloves exhibited a water contact angle of $114^{\circ}$, while hydrophobic properties were also found for textured nitrile butadiene rubber materials $\left(98^{\circ}\right)$. Smooth polyvinyl chloride gloves revealed the highest wettability $\left(64^{\circ}\right)$. The values obtained by those researchers for latex and polyvinyl chloride are comparable to those determined in this study, but the good hydrophobic properties of nitrile gloves noted by both Moore et al. and Łagan et al. were not replicated.

The hydrophobic properties of polymeric glove materials are crucial to user safety, as hydrophobic surfaces decrease the risk of the accumulation of chemical and biological contaminants on the glove surface, which translates into more effective transport of noxious liquid substances outside the glove region. Moreover, imparting hydrophobic properties to materials with good wettability may not only increase their safety due to selfcleaning but also extend their useful life [36].

Another important parameter determining effective hydrophobization is the adhesion of the surface layer, which may differ between polymers. It was evaluated by means of measurements of SFE [37], which is equal to the work needed to form a new unit of surface upon the separation of two phases in equilibrium in a reversible isothermal process, which is expressed in $\left(\mathrm{mJ} / \mathrm{m}^{2}\right)$. SFE is a thermodynamic function [38] describing the equilibrium state on the surface of materials and characterizes every physical object [39]. In this study, SFE was measured using the Owens-Wendt method by determining the polar and dispersive components, which arise from interactions at the liquid-solid interface. The polar component is associated with interactions of mostly chemical nature, such as polar, dative covalent, acid-base, and induction interactions, as well as hydrogen bonds. On the other hand, the dispersive component depends on the dispersion of a liquid and is closely linked to liquid adsorption on the surface of a solid.

In the case of smooth surfaces of the dorsal aspect, all the studied materials revealed high SFE values $\left(>40 \mathrm{~mJ} / \mathrm{m}^{2}\right)$. The observed slight differences are attributable to material properties. The highest SFE was found for nitrile butadiene rubber $\left(69 \mathrm{~mJ} / \mathrm{m}^{2}\right)$, while for the other materials it ranged from $43 \mathrm{~mJ} / \mathrm{m}^{2}$ to $55 \mathrm{~mJ} / \mathrm{m}^{2}$. The polar component was dominant in most cases, with nitrile butadiene rubber being an exception. High SFE naturally leads to good adhesive properties. In addition, increased surface polarity results in greater molecular forces between objects, and thus greater adhesion.

No significant differences in SFE were observed between the palmar and dorsal aspects. The data given in Tables 4 and 5 indicate a relationship between projection height and SFE. The higher the projections, the greater the polar component. High values of the polar component were also associated with irregular textures; this observation indicates that polar compounds form irregular clusters on modified surfaces that arise from strong intramolecular interactions, thus considerably increasing both the surface area and the SFE of the materials.

The energy state of the surface layer of polymeric materials is particularly important in applications that rely on the adhesive properties of the polymers. Increasing SFE is one of the ways of energy activation of the surface layer. A decrease in SFE, and especially in its polar component, which is associated with higher water contact angles, is also crucial in the design with hydrophobic properties [40].

In the case of commercially available protective gloves, it has been shown that hydrophilic surfaces are conducive to greater adhesion of contaminants and their penetration through the glove material to the user's hand. Obviously, protective glove materials should be characterized not only by satisfactory mechanical properties, but also by superior resistance to the accumulation of biological and chemical contaminants on the surface [41].

Adhesion is defined in the literature as a surface phenomenon which consists of the formation of interactions between atoms or particles of two adhering objects/phases. It is therefore 
critical to study phenomena occurring at the interface of objects, especially from the standpoint of the tribological properties of the material [42]. The low energy of adhesion on polymeric surfaces coming in contact with liquids indicates low wettability of the surface layer attributable to weak interactions at the solid-liquid interface [43]. From the point of view of wettability of protective gloves and the potential hazards associated with the adhesion of contaminants to the surface, it is important to determine the strength of the resulting adhesive bonds at the liquid-glove interface. In this context, one can calculate the energy needed to separate the surfaces, and then determine the intermolecular interactions between the phases. While it is important to obtain low overall surface energy to reduce wettability, the individual components of SFE also play a crucial role in the spreading of liquids on the surface.

To improve the hydrophobic parties of polymeric surfaces, it may be beneficial to form submicron roughness. In the case of materials required to provide protection against exposure to non-polar liquids, an effective treatment method could involve anti-wetting modifications involving low levels of the dispersive component. Conversely, in the case of materials intended to provide protection against polar liquids, modifications involving low levels of the dispersive component may be more effective [44]. Statistical analysis of the present results indicated the absence of a correlation between the height of projections on polymeric surfaces and water contact angles. This may be largely attributable to the fact that the projections on the surface of polymeric materials have macro-scale dimensions (Table 2), while wettability properties are usually modified by micro- or nanoscale topographies [45].

The findings revealed a correlation between work of adhesion and wettability for all the studied materials. The higher the wettability, both for polar and non-polar liquids, the higher the work of adhesion. The results given in Tables 4 and 5 show that nitrile butadiene rubber materials exhibit the highest SFE and the greatest work of adhesion with respect to both test liquids, which may indicate that chemical and biological contaminants may accumulate on their surface most readily.

An important objective of biomimetic material design, especially in the case of protective glove materials, is to find an optimum combination of surface physicochemical properties and surface microstructure for a given application, as it has been shown that such properties as wettability and adhesion can be altered by modifying surface morphology on the micro- and nanoscale. From the viewpoint of the occupational safety of polymeric protective gloves, biomimetic materials should combine two important properties, namely reversible adhesion (adhesion via a large number of contact points) and hydrophobicity (repulsion of moisture). The presented results and analysis confirm that biomimetic superhydrophobic polymeric materials with textured surfaces and reversible adhesion properties can be successfully adapted and applied in the design of protective gloves with superior safety performance.

\section{Summary}

The present study on the hydrophobic properties of commercially available polymeric protective gloves led to the following conclusions:

- The studied products had rough, textured surfaces with the mean height of projections being $0.23 \mathrm{~mm}$.

- The geometric structures imparted to the surface led to different levels of hydrophobicity and SFE, improving adhesive properties and decreasing wettability.

- Most of the studied materials were characterized by good wettability properties, with only two latex samples exhibiting water contact angles of $>90^{\circ}$ (the only hydrophobic glove materials). On the other hand, gloves made of nitrile butadiene rubber were hydrophilic.

- It was shown that a textured surface topography (geometric projections) affects wettability, but no significant correlation between projection height and water contact angle was obtained.

- The highest SFE was found for nitrile butadiene rubber materials (also characterized by high work of adhesion), which was four times greater as compared to the other studied materials in the case of the non-polar test liquid.

- All materials except for nitrile butadiene rubber exhibited good hydrophobic properties and relatively low work of adhesion, which may indicate improved resistance to the accumulation of biological and/or chemical contaminants on the surface.

\section{Acknowledgements}

This paper has been based on the results of a research task carried out within the fifth stage of the National Programme "Improvement of safety and working conditions" partly supported in 2020-2022 — within the scope of research and development - by the National Centre for Research and Development (project no. III.PB.12 entitled "The use of biomimetic mechanisms to improve the adhesive and hydrophobic properties of polymeric materials used in protective gloves."). The Central Institute for Labour Protection - National Research Institute is the Programme's main co-ordinator.

\section{References}

[1] Koradecka, D. (2012). Use of personal protective equipment in the workplace. Handbook of Human Factors and Ergonomics, USA John Wiley \&Sons Press. pp. 895910.

[2] Koradecka, D. (Ed.). (2010). Handbook of Occupational Safety and Health. 0 ed. CRC Press; doi: 10.1201/ EBK1439806845. 
[3] Irzmańska, E., Brochocka, A. (2017). Modified polymer materials for use in selected personal protective equipment products. Autex Research Journal, 17(1), 35-47. doi: 10.1515/aut-2015-0040.

[4] Irzmańska, E. (2015). The impact of different types of textile liners used in protective footwear on the subjective sensations of firefighters. Applied Ergonomics, 47, 34-42. doi: 10.1016/j.apergo.2014.08.013.

[5] Adamus-Włodarczyk, A., Bacciarelli-Ulacha, A., Irzmanska, E., Strąkowska, A., Masłowski, M. (2018). Evaluation of the elastomeric composite self-repair process for the construction of protective gloves. Fibres \& Textiles in Eastern Europe, 26, 104-110. doi: 10.5604/01.3001.0012.1320.

[6] Regulation (EU) 2016/425 of the European Parliament and of the council of 9 March 2016 on personal protective equipment and repealing Council Directive 89/686/EEC.

[7] Guidance for the selection, use and maintenance of safety and occupational footwear and other personal protective equipment offering foot and leg protection. 2012.

[8] Krzemińska, S., Irzmańska, E. (2013). Preliminary evaluation of the ergonomic properties of gloves for protection against mineral oils based on manual dexterity tests. Journal of Testing and Evaluation, 41(6), 2012-0224. doi: 10.1520/JTE20120224.

[9] Wolfs, M., Darmanin, T., Guittard, F. (2013). Superhydrophobic polymers. In: John Wiley \& Sons, Inc., (Ed.) Encyclopedia of polymer science and technology, Hoboken, NJ, USA: John Wiley \& Sons, Inc.; p. pst594. doi: 10.1002/0471440264.pst594.

[10] Taleb, S., Darmanin, T., Guittard, F. (2018). Switchable and reversible superhydrophobic surfaces: Part One. In: Kokturk, G., Altun, T. D. A. (Eds.) Interdisciplinary expansions in engineering and design with the power of biomimicry, InTech;. doi: 10.5772/intechopen.73022.

[11] Karasiewicz, J., Dutkiewicz, A., Maciejewski, H. (2014). Fluorokarbofunkcyjne silany jako prekursory materiałów silnie hydrofobowych. Chemik, 68(11), 945-956.

[12] Owens, D. K., Wendt, R. C. (1969). Estimation of the surface free energy of polymers. Journal of Applied Polymer Science, 13, 1741-1747. doi: 10.1002/ app.1969.070130815.

[13] Firas, A., Michael, G., Georgina, K., Bronwyn, F., Paul, P. J. (2009). Adhesion of polymers. Progress in Polymer Science, 34(9), 948-968. doi: 10.1016/j.progpolymsci.2009.04.007.

[14] Brown, H. R. (2000). Adhesion between polymers and other substances - A review of bonding mechanisms, systems and testing. Materials Forum, 49-58.

[15] Liston, E. M., Martinu, L., Wertheimer, M. R. (1993). Plasma surface modification of polymers for improved adhesion: $A$ critical review. Journal of Adhesion Science and Technology, 7, 1091-1127. doi: 10.1163/156856193×00600.

[16] Vincent, J. F. V., Bogatyreva, O. A., Bogatyrev, N. R., Bowyer, A., Pahl, A.-K. (2006). Biomimetics: Its practice and theory. Journal of Royal Society Interface, 3, 471-482. doi: 10.1098/rsif.2006.0127.

[17] Müller, R., Abaid, N., Boreyko, J. B., Fowlkes, C., Goel, A. K., Grimm, C., et al. (2018) Biodiversifying bioinspiration. Bioinspiration \& Biomimetics, 13, 053001. doi: 10.1088/1748-3190/aac96a.
[18] Whitesides, G. M. (2015). Bioinspiration: Something for everyone. Interface Focus, 5, 20150031. doi: 10.1098/ rsfs. 2015.0031.

[19] Bhushan, B. (2009). Biomimetics: Lessons from nature-an overview. Philosophical Transactions of the Royal Society A, 367(1893), 1445-1486. doi: 10.1098/rsta.2009.0011.

[20] Choi, J., Hwang, J., Jeong, Y., Park, J. M., Lee, K. H., et al. (2015). Biomimetics: Forecasting the future of science, engineering, and medicine. International Journal of Nanomedicine, 10, 5701. doi: 10.2147/IJN.S83642.

[21] Fayemi, P. E., Wanieck, K., Zollfrank, C., Maranzana, N., Aoussat, A. (2017). Biomimetics: Process, tools and practice. Bioinspiration \& Biomimetics, 12, 011002. doi: 10.1088/1748-3190/12/1/011002

[22] Sun, M., Liang, A., Watson, G. S., Watson, J. A., Zheng, $Y$., et al. (2012). Influence of cuticle nanostructuring on the wetting behaviour/states on Cicada Wings. PLoS One, 7(4), e35056. doi: 10.1371/journal.pone.0035056.

[23] Barthlott, W., Schimmel, T., Wiersch, S., Koch, K., Brede, M., et al. (2010). The salvinia paradox: Superhydrophobic surfaces with hydrophilic pins for air retention under water. Advanced Materials, 22(21), 2325-2328. doi: 10.1002/ adma. 200904411.

[24] Stańczyk, B., Dobrzański, L., Góra, K., Jach, K., Jagoda, A. (2015). Hydrofobowe pokrycia organiczne na gładkich podłożach $i$ na podłożach $z$ rozwiniętą powierzchnią. Materiały Elektroniczne, 43, 25-34.

[25] Guo, Z. G., Liu, W. (2007). Biomimic from the superhydrophobic plant leaves in nature: Binary structure and unitary structure. Plant Science, 172, 1103-1112. doi: 10.1016/j.plantsci.2007.03.005.

[26] Wenzel, R. N. (1949). Surface roughness and contact angle. The Journal of Physical Chemistry A, 53, 14661467. doi: 10.1021/j150474a015.

[27] Rios, P. F., Dodiuk, H., Kenig, S., McCarthy, S., Dotan, A. (2006). The effects of nanostructure and composition on the hydrophobic properties of solid surfaces. Journal of Adhesion Science and Technology, 20(6), 563-587. doi: 10.1163/156856106777213302.

[28] Bhushan, B., Koch, K., Jung, Y. C. (2008). Nanostructures for superhydrophobicity and low adhesion. Soft Matter, 4(9), 1799-1804. doi: 10.1039/b808146h.

[29]Zalech, W. B. (2015). Samooczyszczające się powierzchnie. Eliksir, 2, 40-43.

[30] Simpson, J. T., Hunter, S. R., Aytug, T. (2015). Superhydrophobic materials and coatings: A review. Reports on Progress in Physics, 78(8), 086501. doi: 10.1088/0034-4885/78/8/086501.

[31] Wolfs, M., Darmanin, T., Guittard, F. (2013). Superhydrophobic fibrous polymers. Polymer Reviews, 53(3), 460-505. doi: 10.1080/15583724.2013.808666.

[32] Firlik, S., Molenda, J., Borycki, J. (2010). Porównanie metod wyznaczania swobodnej energii powierzchniowej polimerowych powłok orientujących cienkie kryształy. Chemik, 64(4), 1-4.

[33] Schrader, M. E. (1995). Young-dupre revisited. Langmuir, 11(9), 3585-3589. doi: 10.1021/la00009a049.

[34] Łagan, S., Markiewicz, M. (2017). Ocena wybranych właściwości fizykochemicznych rękawiczek diagnostycznych. Aktualne Problemy Biomechaniki, 2936. 
[35] Moore, G., Dunnill, C. W., Wilson, A. P. R. (2013). The effect of glove material upon the transfer of methicillinresistant Staphylococcus aureus to and from a gloved hand. American Journal of Infection Control, 41(1), 19-23. doi: 10.1016/j.ajic.2012.03.017.

[36] Atthi, N., Nimittrakoolchai, O., Jeamsaksiri, W., Supothina, S. (2008). Chemical resistant improvement of natural rubber and nitrile gloves by coating with hydrophobic film. Advanced Materials Research, 55-57, 741-744. doi: 10.4028/www.scientific.net/AMR.55-57.741.

[37] Rudawska, A., Jacniacka, E. (2009). Analysis for determining surface free energy uncertainty by the Owen-Wendt method. International Journal of Adhesion and Adhesives, 29(4), 451-457. doi: 10.1016/j. ijadhadh.2008.09.008.

[38] Applied Surface Thermodynamics. (2017). Place of Publication Not Identified: CRC Press.

[39] Hutchinson, A. R., Iglauer, S. (2006). Adhesion of construction sealants to polymer foam backer rod used in building construction. International Journal of Adhesion and Adhesives, 26(7), 555-66. doi: 10.1016/j. ijadhadh.2005.09.001.
[40] Myshkin, N., Kovalev, A. (2018). Adhesion and surface forces in polymer tribology-A review. Friction, 6(2), 14355. doi: 10.1007/s40544-018-0203-0.

[41] Irzmanska, E., Dynska-Kukulska, K., Jurczyk-Kowalska, M. (2014). Characteristics of microstructural phenomena occurring on the surface of protective gloves by the action of mechanical and chemical factors. Polimery, 59(2), 136146. doi: 10.14314/polimery.2014.136.

[42] Wojciechowski, W. (2011). Wykorzystanie pracy adhezji i składowych swobodnej energii powierzchniowej do tribologicznej analizy stanu warstwy wierzchniej. Tribologia, 6, 269-282.

[43] Jeevahan, J., Chandrasekaran, M., Britto Joseph, G., Durairaj, R. B., Mageshwaran, G. (2018). Superhydrophobic surfaces: A review on fundamentals, applications, and challenges. Journal of Coatings Technology and Research, 15(2), 231-250. doi: 10.1007/s11998-017-0011-x.

[44] Song, K., Lee, J., Choi, S.-O., Kim, J. (2019). Interaction of surface energy components between solid and liquid on wettability, and its application to textile anti-wetting finish. Polymers, 11(3), 498. doi: 10.3390/polym11030498.

[45] Wang, J., Wu, Y., Cao, Y., Li, G., Liao, Y. (2020). Influence of surface roughness on contact angle hysteresis and spreading work. Colloid and Polymer Science, 298, 11071112. doi: 10.1007/s00396-020-04680-x. 